\title{
CORRENDO ATRÁS DO PREJUÍZO: O PROBLEMA DO PARADIGMA GEOGRÁFICO DA GEOGRAFIA
}

\section{Making up For Lost Time: the Problem of the Geographic Paradigm for Geography}

Prof ${ }^{\circ}$ Dr. Ruy Moreira

Universidade Federal Fluminense,

Av. Litorânea, s/n, Boa Viagem - Niteroi, RJ - Brasil

Tel/Fax: (+55 21) 26295950/26295950 - ruymoreira@uol.com.br

\section{$a a \boldsymbol{a} a a$}

\section{Resumo}

A dificuldade de se ordenar o discurso num eixo analítico e com formato epistemológico claro e próprio, posto para além da descrição ou agregado de informações geográficas que vemos predominar na generalidade dos textos e manuais, contrariamente à riqueza do léxico que estes mobilizam, se deve à perda da sintaxe geográfica que se deu no âmbito da geografia francesa no começo do século XIX. De que ainda não logramos de todo sair ainda hoje. Fato que se vê na recorrente busca de uma teoria geral para a geografia na história dos últimos cem anos desse saber. E foi a marca recente dos anos 1970.
\end{abstract}

Palavras-chave - Sintaxe discursiva, vazio paradigmático, ciclicidade teórica

\begin{abstract}
The difficulty of arranging a discussion along an analytical axis with a clear and unique epistemological format that extends beyond simple descriptions or the accumulation of geographic information typical of textbooks and manuals, which contradicts the richness of the lexicon that these sources provide, is due to the loss of geographic syntax resulting from the French school of Geography at the beginning of the 19th Century. Even today, we have yet to distance our analytical thinking from this limitation. This is emphasized by the fact that the search for a general theory of geography has already taken more than one hundred years. This has been the recent characteristic of the nineteen-seventies
\end{abstract}

Key words - discursive syntax, paradigmatic void, theoretical cyclicity.

\section{Resumen}

La dificultad de ordenar el discurso en un eje analítico y con formato epistemológico claro y propio, puesto para más allá de la descripción o agregado de informaciones geográficas que vemos predominar en la generalidad de los textos y manuales, contrariamente a la riqueza del léxico que estos movilizan, se debe a la pérdida de sintaxis geográfica que se dio en el ámbito de la Geografía francesa al comienzo del siglo XIX. De que aún no logramos del todo salir todavía hoy. Hecho que se ve en la recurrente búsqueda de una teoría general para la Geografía en la historia de los últimos cien años de ese saber. Y fue la marca reciente de los años 1970.

Palabras-clave - Sintaxis discursiva, vacío paradigmático, ciclicidad teórica.

\section{aaAaa}




\section{INTRODUÇÃO}

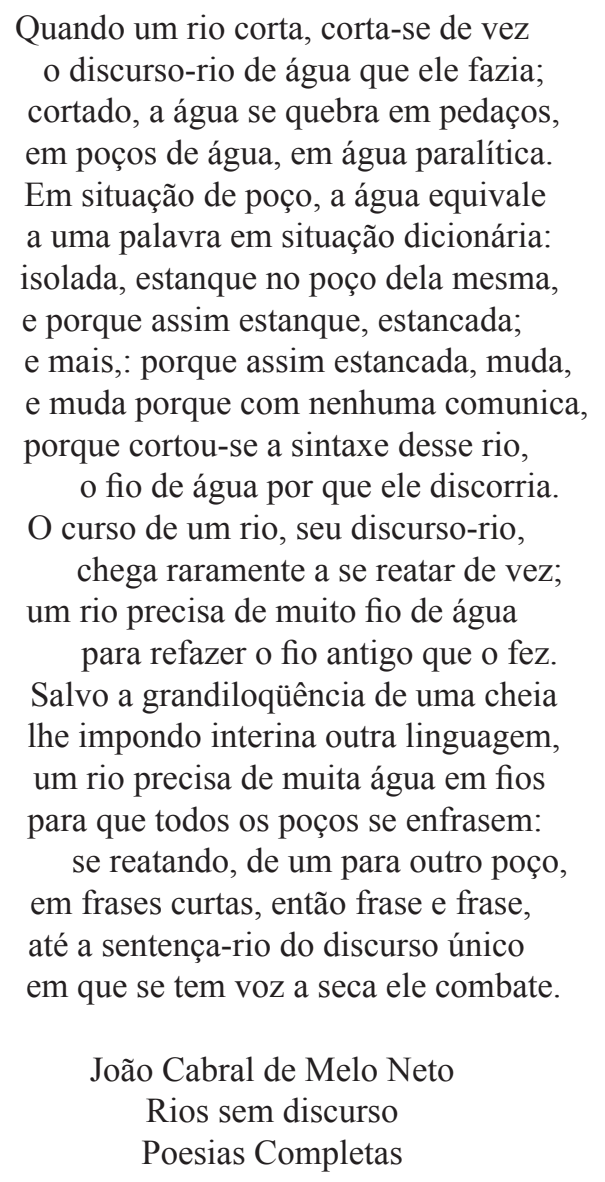

A geografia é um rio que perdeu sua sintaxe. Assim como um rio do sertão nordestino que perde seu prumo e rumo quando o fio contínuo de água corta na seca, vê-se ela como um discurso-rio que corta e busca restabelecer sua inteiricidade, sabendo precisar um rio de muito fio de água para refazer o fio antigo que o fez.

Faz um século vive ela um vazio de alma. A sensação de estar dentro de uma casca, o vale e o leito do rio que só eles se mantêm, vazio da água e do fio d’água-conteúdo. E assim como o rio, busca, desde então, tenazmente, unir no leito que lhe resta os poços que ficaram, sem unidade, desenfrasados, recriando, se não mais é possível resgatar, o discurso-sintaxe perdido. É assim que desde os clássicos aos renovadores recentes sucede a seqüência de pensadores empreendendo o esforço de restabelecer o parâmetro dissolvido, reconferir a sintaxe quebrada, retrazer a presença intelectiva e intelectual perdida (Moreira, 2008, 2009, 2010).

\section{O PROBLEMA E SUA ORIGEM}

Trata-se do efeito de um traço de sua história. Surgido nos últimos cem anos. Em 1898-1899 Durkheim, em pleno trabalho de elaboração do corpus sociológico que o tornaria uma referência do pensamento social moderno ao lado de Marx e Weber, publica no número correspondente do Année Sociologique, por ele criado, uma resenha crítica da Antropogeografia de Ratzel, cujo volume 2 acabara de ser publicado em 1891, junto à reedição rearrumada do volume 1, publicado em 1882, para estar em consonância com o volume 2. Em tom ácido e condenatório, Durkheim desanca a obra de Ratzel, acusa-a de um vazio de conteúdo, qualificando-a de equivocada e ausente de qualquer base de cientificidade desde o termo que escolhe para título.

Tudo teria ficado na resenha-crítica não fora os discípulos de primeira geração de Durkheim, François Simiand, Marcel Mauss e Maurice Halbwachs, terem, a seguir, no correr dos anos 1905 a 
1909, resolvido reproduzir tais críticas dessa vez aos trabalhos de doutoramento recém-divulgados dos primeiros discípulos de Vidal de La Blache, Albert Demangeon, Raoul Blanchard, Camille Vallaux, Antoine Vachere e Jules Sion, aplicando-lhes a mesma acusação condenatória a Ratzel do mestre Durkheim. Vidal ter resolvido acalmar os ânimos dizendo em texto-palestra de 1913, As características próprias da geografia, ser a geografia uma "ciência dos lugares e não dos homens". Lucien Febvre ter tomado a função de árbitro da contenda, demarcando como campos respectivos da sociologia o contexto estrutural das relações societárias, da história o processo temporal, da antropologia o sígnico-cultural e da geografia o infra-espacial do solo (Febvre, 1954). E os discípulos de Vidal terem aceito seja a formulação do mestre e seja a solução pactual oferecida por Febvre como equação teórica, e, sobretudo, tomado A Terra e a evolução humana, um livro subintitulado pelo próprio Febvre como uma Introdução geográfica à história, e não o Princípios de geografia humana, obra póstuma de Vidal, ambos publicados no mesmo ano de 1922, para paradigma e fundamento epistemológico da geografia.

O fato é que face essa demarcação frações inteiras do conteúdo da geografia progressivamente são transferidos para aqueles campos de saberes vizinhos, o fio d'água lentamente cortando diante de um leito-casca lexicalmente quebrado em poças, massa residual do que fora o antigo léxico do discurso-rio.

\section{UM RETORNO A HUMBOLDT E RITTER}

Não tardou que os geógrafos ressentissem seus efeitos. A começar pelo próprio Vidal, através seu supostamente providencial Princípios de geografia humana, mas também Reclus e Ratzel, com inúmeras obras, além de Brunhes, como num quadrado orgânico de recuperação tardia. Suas referências: Humboldt e Ritter, o discurso-rio seminal de tudo.

Sem que apareça explícito como um projeto, mais lembrando as poças de remissão do discurso-rio quebrado, Humboldt e Ritter, citados aqui e ali em recorrências freqüentes, aparecem, recuperados embora numa ida reiterativa e assistemática, como uma referência seminal de fundamentos. Estamos, todavia, sob o signo do neo-kantismo e forte influência hegemônica do positivismo. E é nestes termos que este "retorno aos fundadores" então se dá.

Holistas, Humboldt e Ritter extraem seus olhares do modo como homem e natureza se relacionam no âmbito da superfície terrestre, mas diferindo no ponto de partida e de chegada. Humboldt foca seu olhar no modo como as esferas do inorgânico, do orgânico e do humano reciprocamente interagem e se transfiguram enquanto momentos e formas do movimento da matéria. Centrando sua leitura na mediação para baixo (na relação com o inorgânico) e para cima (na relação com os animais e o humano) das plantas e na forma como por meio dessa mediação se dá o todo do movimento fenomênico, Humboldt, indo da relação homem-natureza para a relação homem-espaço e daí voltando para a relação homem-natureza, toma a configuração territorial das paisagens da vegetação (o que chama a geografia das plantas) como referência, sobre ela se debruçando para então flagrar a interação das esferas, descrevê-la e analisá-la na sua realização em geografia. Ritter como que empreende o movimento do olhar inverso. Tomando como referência o recorte paisagístico já então formado, vai da relação homem-espaço para a relação homem-natureza, para num retorno à relação homem-espaço flagrar o processo de interação das esferas como movimento constitutivo de diferenciação de paisagens (que chama de geografia comparada) que organiza a superfície terrestre como um grande mosaico corográfico de individualidades regionais. A paisagem é assim o recurso analítico de ambos. Humboldt visualizando-a no entrecortado fisionômico e estrutural das formas de vegetação. E Ritter no mosaico dos entrecortes que fazem o todo das paisagens se diferenciar num múltiplo de formas particulares de recortes espaço na superfície terrestre (Moreira, 2006). 


\section{A REFUNDAÇÃO}

Inspirados em tal paradigma, mas cuidando de substituir o holismo que o informa pela integração pura e simples, os pensadores clássicos separam a relação homem-natureza e relação homem-espaço em dois eixos diferenciados, associando Humboldt ao primeiro e Ritter ao segundo, numa dicotomização do todo até então unificado de homem-espaço-natureza da sintaxe humboldt-ritteriana, numa busca contraditoriamente incansável de superar essa dicotomia enquanto conseqüência em si da o própria sintaxe perdida. Um projeto que aos poucos se concretiza, numa sintaxe que, entretanto, sempre circunda o holismo humboldt-ritteriano sem conseguir recuperá-lo em sua feição originária. Sabem ter nacos do antigo discurso-rio se transferido e materializado no senso público como discurso-rio da sociologia, da história, da antropologia. E ter de reavaliar o ato inaugural da geografia moderna, amortecido pelo ocaso do romantismo filosófico em que se haure, embora dispondo do essencial de suas fundações, ainda incólume. Resta, pois, mesmo que como casca, a grande calha da relação homem-espaço-natureza do antigo leito humboldt-ritteriano. E, num enorme esforço de reconstrução discursiva, juntar, então, frase e frase, as poças d água restantes, dispersas e heteroclitamente espalhadas ao longo do curso quebrado, em uma nova e possível sintaxe. Lenta, mas efetivamente, o velho fio d’água assim vai sendo reatado.

Vem de Brunhes - um geógrafo posto na fronteira da França e da Alemanha e assim livre do vírus de acometimentos do possibilismo versus determinismo, demarcações e denegações críticas da tipologia de Durkheim-Febvre - o primeiro formato sistemático de recuperação, através o seu Geografia humana, de 1910. Sob o signo do privilégio desse convívio, realiza, assim, via incorporação seja de Humboldt e Ritter e seja de Vidal e Ratzel uma formulação sintáxica em que a relação homem-natureza se faz relação homem-espaço, a relação homem-natureza se integralizando num todo de feição geográfica na materialidade existencial das formas concretas da relação homem-espaço.

O ponto de partida é, pois, a relação homem-natureza. O homem distribui-se acompanhando a distribuição das plantas e das águas na superfície terrestre, diz Brunhes, estabelecedendo-se uma relação homem-planta e uma relação homem-água que, às vezes justapostas e às vezes separadas que para frente se encontram, vão formam a base da base da organização espacial das sociedades em cada lugar. É dessa relação homem-planta-água que se erguem com o tempo as casas e os caminhos. Da conjuminação das casas nos cruzamentos dos caminhos nasce a cidade. Dos interstícios dessa ossatura de casas, caminhos e cidades brotam as manchas das culturas e criações, que o sistema de circulação integra numa só estrutura unitária. De que brotam as indústrias como forma adiantada de resultados, numa afirmação consolidada do todo geográfico. E desse arranjo de espaço nasce o habitat do homem, identificado por sua forma própria de paisagem enquanto modo de ser-estar geográfico da humanidade.

Sucede que este habitat é uma relação espacial pontual de uma superfície terrestre comandada no seu conjunto pela oposição contraditória da ação da força louca do sol e sábia da terra que a mantém num estado permanentemente de desordem e ordem, a desordem termodinâmica do sol e a ordem do peso gravitacional da terra, com o qual o homem vai ter que saber lidar e usar em seu proveito. Onipresente na superfície terrestre, essa contradição geral vai desdobrar-se em duas outras, de cunho local e regional, respectivamente. É assim que ao transformar sua relação com a natureza em uma relação de espaço, o homem constrói este destruindo aquela, fazendo-o numa dinâmica de desordem-ordem de novo tipo e nível de escala em que destrói para construir e constrói por destruição, numa relação de estabilidade-instabilidade que precisa também saber por em movimento. E também é assim que ao construir o espaço distribuindo por sua extensão casas, caminhos, cidades, manchas de culturas-criações e indústrias de modo diferenciado segundo indique o acompanhamento das escalas de contradições maiores, forma um todo de cheios e vazios que se trocam continuamente, os cheios virando vazios e os vazios virando cheios numa alternância redistributiva que no limite pode congestionar e desarrumar a própria ordem de arranjo coabitante do espaço. 
Vidal de um certo modo interage, ao tempo que como que detalha com seu Princípios de geografia humana, escrito pouco depois do Geografia humana, porém só publicado em 1922 por força de sua morte em 1918, com esta sintaxe em si impressionante de Brunhes.

O ponto de junção é a relação homem-planta também como ponto de partida, o peso da relação homem-água juntando-se com a primeira numa relação homem-planta-água que vai ser a base do erguimento geográficos da sociedade. O âmbito, entretanto, é o que Vidal designa as oficinas da civilização, uma combinação do que chama de áreas laboratórios e áreas anfíbias, enquanto expressões de distintos momentos e recortes e fases de espaço que são já o processo de construção dos habitats humanos, a área laboratório encarnando a fase inicial de aprendizado e acumulação, via um processo inicial de domesticação e aclimatação de plantas e animais em suas migrações entre áreas microclimáticas de uma mesma mesorregião climática, dos conhecimentos e poder de conversão da relação homem-natureza que a seguir vai levar para as grandes áreas dos vales fluviais para com apoio nesse acúmulo de conhecimentos da dinâmica da relação homem-natureza transformar nos grandes espaços e paisagens das civilizações construídas.

A coabitação espacial é o princípio desse erguimento. E o gênero de vida o seu princípio de regulação. Da experiência e acúmulo relacional regulares dessa sua lida com o meio saem as formas de ação técnica. E os hábitos e costumes que transformados em regras e normas vão servir de meios de regulação do todo das relações, assim nascendo os gêneros e seus correspondentes modos de vida. Reguladas nessas regras e normas de coabitação, constróem os homens a cultura cujos valores vão a argamassa de unidade e distinção das civilizações. Pontos com que Vidal parece estar, enfim, anos depois, respondendo aos embates e pactos do começo do século. E esclarecendo o significado de sua controvertida frase de 1913. O lugar é a morada do homem. E, o gênero de vida o fundamento dessa morada. Léxico geográfico que Vidal só aqui e agora explicita.

Ratzel prima por um discurso semelhante, assentado, porém, no que chama de solo. O lugar de habitação humana é a integralidade relacional do todo dos elementos locais da superfície terrestre que o compõe, esta integralidade relacional estabelecida como um modo de vida lugarizado formando seu solo, pedaço de chão que forma seu espaço vital. As regras exigidas para regulação desse convívio e destinadas a forjar de modo integrativo pela coabitação do solo a unidade das relações de vida do coletivo humano são a origem do Estado. A coabitação assim estabelecida a partir e pelo Estado é a sociedade. E é essa inteireza e modo orgânico de relação homem-espaço-natureza a antropogeografia.

Não deixa de ser ironia Febvre ter reduzido a sintaxe geográfica ao solo, justamente por onde passa a de Ratzel. Mal compreendida, seja por ele e seja por Durkheim. Talvez porque haja uma genuinidade que nele dá um sentido profundamente diferente de significado ao elenco de termos cujo exemplo conspícuo é justamente o de solo - que neste momento está chegando para formatar a fundação das ciências humanas - justamente as áreas que são envolvidas em contenda -, a síntese e o conceito antropogeográfico de Ratzel se particularizando por essa peculiaridade de idéias e entendimentos que é só dele.

É com Sorre que a ressituação lexical e sintáxica por fim se sintetiza, através seu Os fundamentos da geografia humana, obra em três volumes publicada entre 1943 e 1962 e por ele posteriormente resumida no O homem na terra, de 1962. Com Sorre a sintaxe do discurso-rio ganha o sentido da complexidade. Um discurso de estrutura de relações espacialmente acumulativas cujo resultado é um crescendo de sociabilidade.

Da relação homem-planta e relação homem-água face seu vínculo com as necessidades básicas do homem deriva a relação homem-planta-água da geografia agrícola. Já em si marcada nesse conteúdo de intencionalidade, da geografia agrícola deriva a geografia da alimentação com seus distintos regimes alimentares. A reiteração contínua seculariza essas relações nos valores permanentes de que emergem os hábitos e costumes. Da vertente ambiental desses valores derivam as habilidades e artefatos que se entronizam em relações técnicas. E da vertente ética as regras que 
exprimem as relações de regulação que normatizam as relações homem-homem e homem-meio em seus entrosamentos de conjunto. Que tudo transforma em relações de sociabilidade. Segue o desenvolvimento dessa estrutura rumo às relações técnicas mais desenvolvidas da indústria. A rearrumação distributiva de homens e coisas entre campo e cidade que emana das relações industriais. A sociabilidade urbana. E as relações de planetarização do ecúmeno humano. Do plano seminal do arranjo do espaço de base intra-natural ao mais acabado da sociabilidade urbano-industrial, relações de todos os tipos se entrecruzam e assim se embutem, fazendo de cada nível um complexo, do espaço uma estrutura de espessura em crescendo, do conjunto estrutural uma rede de complexidades e do ecúmeno terrestre um complexo de complexos.

Chegados a Tricart e George esta sintaxe como que pode dividir-se agora nos eixos sobre os quais nascera, como que pedindo um mergulho de detalhamentos e elucidações, de um lado para o fim de uma elaboração mais definida das relações homem-natureza e homem-espaço num modo que resgate em minúcias como fora com Humboldt e Ritter ao tempo que os atualize para a contemporaneidade e de outro para o de uma reaglutinação que agora os unifique sobre as novas bases. Como num ritual de passagem.

Tricart é o esmiuçamento do olhar sobre o eixo homem-natureza, numa nítida reintrodução da teoria das três esferas e da mediação da geografia das plantas de Humboldt, desde a recuperação esmaecida como fio d água do seu discurso-rio, tal como a apresenta na Terra planeta vivo, de 1972, mas, sobretudo, Ecodinâmica, de 1977. Visualizada nestes termos, mas mergulhada numa relação dialética posta para além da sintaxe do uno-diverso simples de Humboldt, a superfície terrestre é vista agora numa relação natureza-homem sacudida de forma permanente por quatro ordens de contradição, cujos termos Tricart vai buscar na A dialética da natureza, de Engels. À base dessa relação, no ecótopo, como à guisa de uma infraestrutura, diz, contraditam a morfogênese e a pedogênese, movimentadas num moto contínuo pela ação incessante do intemperismo. A ação da morfogênese tende à retirada e redistribuição territorial do material intemperizado pela erosão, afetando a condição de possibilidade de constituição do processo de pedogênese, igualmente informado no manto do intemperismo como matéria prima. O impedimento da transformação dessa potencialidade em ato é a presença da vegetação, fixadora do material intemperizado e contribuidora para sua conversão em solo, controlando o processo erosivo da morfogênese e regulando sua relação de tensão com a pedogênese mercê sua ação fitoestásica. Mas é uma contradição que se retroalimenta na ação de outra maior, de escala planetária, que é a oposição incessante das forças internas, de natureza geológica, e forças externas, de natureza climática, responsáveis nos seus embates pela formação justamente no plano daquela da ação do intemperismo. De caráter planetário, responde pela movimentação do modelado do relevo terrestre, e tudo de que este parte e envolve. Dela é que vem a ação reiterada do intemperismo, a intervenção destruidora da erosão e a função de acomodamento da sedimentação, enquanto plano global do movimento de transformação recíproco de matéria e energia no todo da superfície terrestre, que escapa a qualquer controle, mesmo o fitoestásico, deixando o plano pontual da contradição ecotópica num estado dialético de instabilidade-estabilidade permanente. Em posição de escala intermediária, age a terceira contradição, em que se opõem o ecótopo e a biocenose, onde também intervém a ação fitoestásica da cobertura vegetal. É, assim, uma escala de contradição que amplia o raio de ação e função reguladora da fitoestasia, a vegetação articulando nesse plano os seus dois aspectos de oposição ao enraizar-se num - a "infraestrutura" ecotópica - e desenvolver seu corpo noutro - a "superestrutura" biocenótica -, integrando-os e acasalando-os na ciclicidade da retransfiguração recíproca do biótico-abiótica do meio, através a relação simultânea e oposta da fotossíntese e da decomposição bacteriana. É onde intervém a quarta contradição, a que se dá entre o todo ecossistêmico do ecótopo-biocenose e o específico do modo histórico-concreto de produção existente, na qual o homem, à exemplo do duplo modo de inserção da vegetação da terceira contradição, é um duplo presente, aqui como um ente biocenótico e ali socioeconômico, e nesse termo se move enquanto relação homem-natureza, entrando na dinâmica de interação das esferas 
humboldtianas, no lugar da esfera intermédia e função fitoestásica da geografia das plantas, como uma espécie de sujeito-condutor-regulador via controle do meio através o domínio do movimento da cadeia trófica.

Tricart está aqui retomando e dando novo contorno e vigor sistemático à teoria das três contradições de Brunhes, ao tempo que à teoria de regulação do gênero de vida de Vidal, juntando Humboldt, Brunhes e Vidal numa só sintaxe. A contradição de escala geral das forças internas-externas reproduz e detalha o que em Brunhes é a contradição planetária entre a força "louca", desordenadora e desestabilizadora, do sol, e a força "sábia", ordenadora e estabilizadora, da terra. A contradição da escala pontual da oposição morfogênese-pedogênese e regional do ecótopo-biocenose reproduzem e detalham o que em Brunhes é a contradição construção-destruição do espaço, o princípio de ordem-desordem visto agora como "lei" espacial-geográfica territorialmente explícita. E a escala regional-nacional da contradição ecossistema-modo de produção reproduz e detalha o que em Brunhes é a contradição cheios-vazios que leva Brunhes e Tricart a tomar por mirante do espaço como um espaço dinâmico a distribuição, mirante de um olhar dinâmico, e não a localização em si mesma, mirante de um olhar fixo e paralisante, resgatando o arranjo do espaço como uma das "poças d'água" rittero-humboldtiana (a geografia das plantas de Humboldt e o recorte do espaço de Ritter) como o ponto de leitura teórica e metodológica e como momento em que os eixos homem-natureza e homem-espaço se trocam reciprocamente no fazer geográfico.

E sob essa forma também compartilhando da visão sui generis e antecipatória de Brunhes da teoria da energia dissipativa, de hoje, Brunhes desdobrando como discurso geográfico a anteposição dinâmica-termodinâmica que desde 1850 com a descoberta da segunda lei da termodinâmica contradita Newton e Clausius quanto ao estatuto ontológico da natureza e do seu modo real de movimento, Brunhes visualizando nestes termos uma geografia integrada pensada à luz da dialética de ordem-desordem e estabilidade-instabilidade que só décadas depois, mais à frente, em 1927, com o princípio da incerteza quântica de Heisenberg, vai orientar o pensamento científico moderno (Prigogine e Stengers, 1984).

George por sua vez é o esmiuçamento do olhar sobre o eixo homem-espaço, numa recuperação do discurso-rio de Ritter centrado no papel ordenador metodológico e teórico do recorte espacial, em George inscrito como o papel essencialmente espacial, a rigor tecnoespacial, dos arranjos locacional-distributivos dos fenômenos sobre a organização geográfica das sociedades. Se o objeto do detalhamento de Tricart é o miolo formado pela relação de essência homem-natureza, o de George é o formado pela relação concreta de existência homem-espaço daquela, enfim geograficamente realizada, tal como vemos em Sociologia e geografia, de 1969, obra sintética do próprio léxico e sintaxe de George e a mais brunhiano-sorriana de suas obras, o título expressando o quanto o incomodam e o envolvem na busca de superação o imbróglio e o esvaziamento do discurso-rio do começo do século.

É a organização espacial das sociedades produzida como materialidade existencial da relação do homem com a natureza que as qualifica como um real-concreto na história. Isto porque o espaço é que recria, sob outro contexto concreto de história, a social do homem, o entorno organizacional de cunho histórico-natural, indicando por seu grau de transfiguração o grau histórico de progressão e resolução de demandas do homem em sociedade. A técnica é o fator determinante desse movimento, o tempo da técnica substituindo o tempo natural e fazendo via sua transfiguração em espaço da relação homem-natureza o real-concreto em cada contexto efetivo de sociedade. É assim que se passa do tempo-espaço das "sociedades de natureza sofrida" para espaço-tempo das sociedades de espaço organizado, como resume em A ação do homem, de 1968. Fácil ver nessa sintaxe o modo como George repete o que se tem na passagem das áreas laboratórios para as áreas anfíbias como marco de nascimento das civilizações da teoria de Vidal, onde dos pequenos planos de relação homem-natureza brotam os acúmulos de experiência técnica e relacional que os costumes sistematizam em regras e normas de regulação, e em sua progressão para estágios mais evoluídos, que 
George designa de desenvolvimento das forças produtivas, ganham a escala que conduz mais à frente os homens a se deslocarem para as terras baixas das áreas anfíbias, onde os gêneros de vida incorporam mais amplitude e consistência a relação homem-natureza, resolvendo-a nas formas avançadas de relação homem-espaço das grandes civilizações.

\section{DANDO A PALAVRA AO ARRANJO ESPACIAL E À HOMINIZAÇÃO MARXISTA}

Tricart e George são marxistas. Ou, daí egressos, como George. E pensam nos seus termos. É, todavia, com a incorporação, mais à frente, do Marx do Manuscritos de 1844 e de O Capital que os léxicos e as sintaxes do eixo "humboldtiano" da relação homem-natureza de Tricart e do eixo "ritteriano" da relação homem-espaço de George que o movimento de restauro da unidade humboldt-ritteriana do discurso-rio dos clássicos é retomado, tomado o marxismo como base. Retomada que vem, entretanto, aqui na forma de uma ecologia política, pouco ou quase nada na verdade vocacionada na sintaxe tricartiana de relação homem-natureza, e de uma economia política do espaço, georgianamente mais explícita, de todo modo um e outro se oferecendo como alternativa de refundição efetivamente. Daí que a sintaxe tecnoespacial de George se desdobre na teoria das três naturezas/três espaços de Smith ou do espaço produto da técnica e do conceito de tempo-espacial de Milton Santos. Que a espaçoambiental de Tricart se desdobre na teoria da ruptura ecológico-territorial de Quaini. E, ao fim, conflua-se em teorias como a da geossociabilidade de Silva. E se explique o papel essencial inicial de criticidade da sintaxe geográfica anarquista de Reclus, deixada inteiramente de fora das reaglutinações humboldt-ritterianas.

É através o conceito de arranjo espacial de George e da hominização autopoiética do Marx que a busca do discurso-rio, apoiada agora explicitamente numa combinação das sintaxes "ambientais" de Tricart e "espaciais” de George, ver-se-á por excelência retomada (Moreira, 1982). A presença integradora do arranjo do espaço se faz inicialmente no âmbito da economia política, só lentamente chegando à ecologia política, na defasagem que se estabelece neste momento entre ambas vertentes. Com a chegada do conceito de autopoiéses, introduzido só a seguir, e essencialmente, no âmbito da vertente da ecologia política, a sintaxe da relação homem-natureza ganha de imediato uma dimensão holista, a ela depois integrando-se o conceito de arranjo do espaço. É quando a unidade de discurso-rio do todo dos eixos e vertentes se estabelece, estruturando-se por fim o plano integralizado da sintaxe geográfica .

Vem de George, na tradição de Brunhes, a noção do valor do arranjo espacial como elemento chave do discurso-rio geográfico, lido porém nos termos do conceito de estrutura de Marx. Visto por este prisma, o arranjo do espaço adquire o significado do olhar estrutural da sociedade, sua estrutura interna revelando-se na forma do arranjo do espaço. O plano dessa aglutinação é a concepção, de inspiração lefebvriana, certamente, do espaço como o histórico-produzido de Milton Santos, resumida na noção epistemológica da sociedade e do espaço como espelhos de revelação recíproca. O modo de produção da sociedade é o modo de produção do seu espaço. Produzindo-se o espaço, produz-se a sociedade. E vice-versa. Daí decorre a compreensão que de imediato se tira de relação de igual reciprocidade entre o arranjo espacial e a estrutura da sociedade, ontologicamente iguais, onticamente distintas.

É isto o arranjo dos bairros do espaço urbano moderno, revelando em sua distribuição em bairros de ricos, bairros de classe média e bairros de pobres a estrutura de classes e o conteúdo capitalista das cidades. O mesmo se diga do arranjo geral, expressando-se no caráter e fisionomia dos objetos distribuídos no espaço o modo estrutural do processo produtor e os esquemas de reprodução acumulativa. Idem as estruturas jurídicas, política, culturais e ideológico-representacionais que informam o nível superestrutural desse arranjo econômico (Moreira, 1980). Lendo-se o visível, lê-se o invisível, e vice-versa, diz George, na origem de Milton Santos, falando dos planos de configuração da relação homem-espaço. 
Mas é pelo arranjo do espaço que a seguir se percebe realizar-se, e através dele ler-se e intervir, estruturalmente a relação homem-natureza. É por meio das configurações do arranjo que se move e se regula a relação do homem com a natureza, em toda a complexidade de movimento e tensões apresentada por Tricart. Se esta no seu todo se move e se autorregula em termos de fotossíntese através a esfera orgânica da geografia das plantas, é pelo modo de produção que atuando por sobre o todo das esferas e trazendo para este a centralidade das relações que o homem em sociedade - como sujeito, pois, nunca como um "fator antrópico" - move e regula o todo relacional, agora por meio da cadeia trófica, por cujo intermédio incorpora a função fotossintética e fitoestásica da geografia da plantas, encadeando e re-encadeando na forma dos arranjos do espaço o modus operandi e os rumos do todo da relação homem-natureza.

Levou-se, entretanto, um tempo para unir-se esta ecologia política e aquela economia política do espaço, o olhar marxista da relação homem-natureza de Tricart e da relação homem-espaço de George em seus exercícios de explicitação e esmiuçamento sendo a ponte, todavia unidos no conceito metabólico do trabalho (Moreira, 1980).

O trabalho é aí concebido como a troca metabólica que se passa entre o homem e a natureza no âmbito interno desta como entre forças e coisas naturais, com a propriedade de por este meio o homem transformar a natureza transformando-se a si mesmo, hominizando - vai-se dizer mais à frente socioambientalizando - nesse passo o entorno natural e a si mesmo, tudo na conformidade do modo de arranjo do espaço onde isto está se dando. Este salto da história natural em história social em que o homem se naturiza ao tempo que a natureza se historiza - tematizado à saciedade por Quaini e Silva, é foco e a forma do movimento que distingue ôntica ao tempo que funde ontologicamente a relação homem-natureza e a relação homem-espaço, Humboldt e Ritter, enquanto momentos e escala da sintaxe geográfica.

O discurso-rio, por fim, reaparece, fruto do encontro do fio d’água que une as poças do antigo rio cortado, reenfrasadas numa perspectiva cujo olhar tão holista-integrado quanto o antigo vai buscá-la na mesma fonte do romantismo filosófico de Humboldt-Ritter, lido embora no berço ontológico das determinações natural-social concretas da história.

\section{CONSIDERAÇÕES FINAIS}

Homem, espaço e natureza são o léxico do paradigma assim formado, e que se exprime por diferentes formas de sintaxe, assim como era com Humboldt e Ritter. Partindo da estrutura homem-espaço-natureza, que significa homem e natureza interrelacionados em termos de espaço, destes, cada clássico compõe sua sintaxe com variações. Até que a construção originária vê-se reaparecer no discurso metabólico assentado na concepção de trabalho de Marx.

O arranjo do espaço é o ponto de partida e o ponto de chegada dessa forma paradigmática em princípio readquirida. Tal como na geografia das plantas, em que estas eram analisadas em seu papel para baixo e para cima a partir do seu modo de ordenamento espacial, é o mapa da distribuição que serve de referência de método e o que a análise deve explicar, visto porém agora como a elucidação da estrutura oculta do real que se expressa no visível no modo de arrumação do arranjo espacial.

É o metabolismo estabelecido entre o homem e o meio no âmbito seminal das relações intra-natureza de que o homem faz parte como um ente natural entre os demais entes naturais, o tema da análise. Todavia, visando flagrá-lo no seu modo espacial de existência. Expressão mais sintética desse todo e o plano que melhor o capta em seu movimento singular e de conjunto, a geografia das plantas segue sendo o eixo da leitura. Como o foi em Humboldt, Brunhes, Vidal, Sorre e Tricart, embora deixando de sê-lo em Ritter, Ratzel, Reclus e George, e há tempos aplicada ao Brasil por Waibel (Moreira, 2011). Dela se partindo e vindo através as pontes que fazem suas ligações para baixo e para cima. Para baixo, agregando os planos da "geografia física". Para cima os da "geografia humana". No todo, agregando a inteireza dos planos no modo espacial de existência. O modo de 
estar (o arranjo) esclarecendo o modo de ser, tal como no duplo a um só epistemologia-ontologia em que no fundo consiste a sintaxe geográfica de Humboldt.

Se o eixo vertical das conexões referenciado ao movimento do todo das plantas é o mote do método, as tensões que comandam esse movimento é o que se busca apreender, uma vez que do seu conhecimento é que se pode agir sobre os desequilíbrios, formular planos de superação, avaliar tendências. Vale como modelo, lido à luz da quarta contradição, o discurso de instabilidade-estabilidade/potencialidade do Ecodinâmica de Tricart, em sua leitura "do físico" inspirada na leitura "do humano" de Brunhes,

A aposta é a recuperação da capacidade de produzir totalidades que referenciem capacidades de produzir conhecimento do pontual/areal em que a perda da reflexão holista dos fundadores de certo modo jogou num hábito a reflexão em geografia destes cem anos pós-pactual do começo do século XX. A habilidade de teorizar seja sobre as macro e seja sobre as micro escalas, no sentido dos economistas, que reponha a reflexão geográfica na senda das grandes análises, sem as quais não se elucida e se encaminha solução real para nada.

\section{REFERÊNCIAS BIBLIOGRÁFICAS}

FEBVRE, Lucien. A terra e a evolução humana. Introdução geográfica à história In: Panorama da geografia, v. II. Lisboa: Cosmos, 1954.

MOREIRA, Ruy. Espaço e trabalho: a forma e a essência da geografia/O espaço do capital: a produção capitalista do espaço. In: O que é geografia. São Paulo, Editora Brasiliense, 1980 (2a . edição revista e ampliada: 2009).

MOREIRA,Ruy. Geografia, ecologia, ideologia: a "totalidade homem-meio" hoje. In: Geografia: teoria e crítica - o saber posto em questão. Rio de Janeiro: Editora Vozes, 1982.

MOREIRA, Ruy. A geografia serve para desvendar máscaras sociais. In: Pensar e ser em geografia. São Paulo: Editora Contexto, 2007 (1ª. Edição: 1878).

MOREIRA, Ruy. Para onde vai o pensamento geográfico? São Paulo: Editora Contexto, 2006.

MOREIRA, Ruy. O pensamento geográfico brasileiro: as matrizes clássicas originárias. São Paulo: Editora Contexto, 2008.

MOREIRA, Ruy. O pensamento geográfico brasileiro: as matrizes da renovação. São Paulo: Editora Contexto, 2009.

MOREIRA, Ruy. O pensamento geográfico brasileiro: as matrizes brasileiras. São Paulo: Editora Contexto, 2010.

MOREIRA, Ruy. Sociedade e espaço geográfico no Brasil. Constituição e problemas de relação. São Paulo: Editora Contexto, 2011.

PRIGOGINE, Ylia; STENGERS, Isabelle. A nova aliança. Brasília: Edunb, 1984.

VIDAL DE LA BLACHE, Paul. As características próprias da geografia. In: Perspectivas da geografia. CHRISTOFOLETTI, Antonio. São Paulo: Difel,1978.

Trabalho enviado em agosto de 2011 Trabalho aceito em outubro de 2011 